\title{
Ground Fault Protection Methods for Distribution Systems
}

\section{Abstract}

The system grounding method option has a direct influence on the overall performance of the entire medium voltage network as well as on the ground fault current magnitude.

For any kind of grounding systems: ungrounded system, solidly and low impedance grounded and resonant grounded, we can find advantages and disadvantages. A thorough study is necessary to choose the most appropriate grounding protection system. The power distribution utilities justify their choices based on economic and technical criteria, according to the specific characteristics of each distribution network. In this paper we present a medium voltage Portuguese substation case study and a study of neutral system with Petersen coil, isolated neutral and impedance grounded.

\section{Introduction}

The system grounding in power distribution substations is an important issue for the proper operation of the entire network. Main goals of system grounding are to minimize voltage and thermal stresses on equipment, provide personnel safety, reduce communications system interference and give assistance in rapid detection and elimination of ground faults.

The choice of neutral systems has influence on the distribution network performance and on the choice of installed equipment protection. The main differences among neutral systems are related to the network behaviour in case of a ground fault.

There is a wide range of neutral grounding systems in MV distribution networks. The neutral conductor can be connected to ground through different ways, according to the type (capacitive, resistive or inductive), and with its value (0 to infinite). Isolated neutral eliminates the fault current flow to earth through the neutral conductor but causes high voltages. The solidly earth neutral (directly connected to earth) minimizes the voltage surge but it results in high current values.

The resonant-grounded has gained popularity in recent years in distribution networks, mainly due to the significant increase in continuity service [1]. A reactance is installed, known as the Petersen coil, which permits the adjustment of the inductance value to preserve the tuning condition of the system for different network topologies. The variable reactance is connected to the secondary neutral power transformer or to the neutral of a grounding bank [2].

This grounded system protection is particularly advantageous in rural areas, to solve the occurrence of lightning, birds and tree branches caused faults. In urban areas, with mostly permanent faults, resonant grounding system can also be used to guarantee electrical service continuity.

Resonant grounding provides self-extinction of the fault arc in overhead lines for about $80 \%$ of temporary ground faults [3]. Considering that about $80 \%$ of ground faults are temporary, we conclude that more than $60 \%$ of overhead line ground faults clear without breaker tripping. Highimpedance grounded systems are grounded through a highimpedance resistor or reactor with an impedance equal to or slightly less than the total system capacitive reactance to ground. The neutral resistor is of such a high value that ground faults on such systems have very similar characteristics to those of resonant-grounded systems [4-5].

In the next sections we will see different grounded systems and we will analyze their influence on the occurrence of a line-to-ground fault, and the influence of direct and resistive faults at different network points. 


\section{Earthing Ground Systems}

\subsection{Isolated Neutral}

A network is called isolated neutral when there is no physical connection between the neutral point of the MV transformer and earth (Fig. 1).

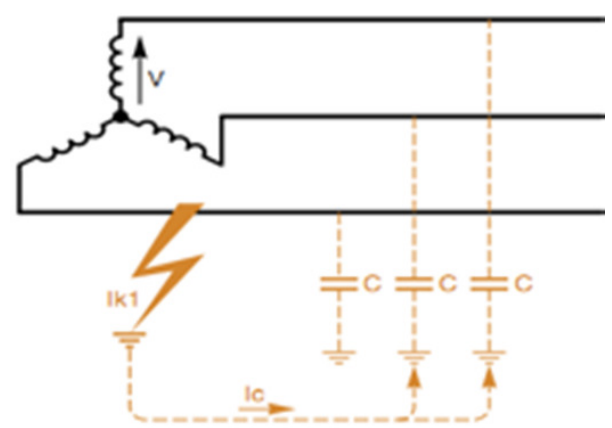

Figure 1. Earth fault in isolated neutral system

The average voltage depends on the impedance between line conductors and the ground. This impedance includes the predominant capacitances between the lines and earth and leakage impedances of other network components [6].

The residual voltage, which is the vector sum of the three line-to-line voltages, is never entirely zero. Monitoring this residual voltage can be a good solution, because it indicates the insulation quality, since any fault between line and earth causes a strong imbalance between the impedance and the increase of residual voltage. This system is mainly used in aerial and short length distribution lines. In the case of long distances, the capacitance to ground is very high, causing dangerous situations due to high current values. Because of the line-to-line voltage, the network must be isolated between phases and earth [7].

The fault current Ik1 can be determined as 3.C.w.V, where, C is the capacitance between line and earth, $w$ is the angular frequency and $V$ is line-to-earth voltage.

The main advantage of this system is the service continuity, because fault current is low and not enough to trigger the automatic protections, which occurs only at a second fault. The disadvantage is the inability to eliminate an overvoltage transient across the earth, which can be a big problem if the voltage is too high.

\subsection{Solidly earthed neutral}

In this case, the connection between neutral point and earth is a straight line with zero impedance (Fig. 2). The network impedance, the fault and earth return set the fault values.

Usually, the current intensity of a large number of ground faults can show significant variations depending on the location and on the kind of fault, making it more difficult to reconfigure the network [3]. In this case, line-to-ground voltage is applied to fault, and the neutral potential remains the same as the earth potential. Upon the occurrence of this fault, a large amount of energy is released [4]. The line-toground fault current is a short-circuit line-neutral, and this value can be high enough to trigger protections at the first fault.

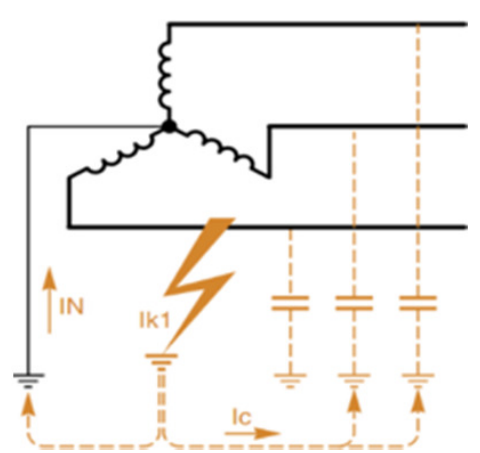

Figure 2. Earth fault in solidly earthed neutral power system This system is very good to eliminate overvoltage's but brings danger to people and service continuity does not exist in case of a fault.

The single-phase earth fault current in a solidly earthed system may exceed the three-phase fault current. The magnitude of the current depends on the fault location and the fault resistance. One way to reduce the earth fault current is to leave some of the transformer neutrals unearthed. The main advantage of solidly earthed systems is low overvoltage's, which makes the Earthing design common at high voltage levels [8].

\subsection{Impedance Earthing}

This method uses an impedance, which can be a resistor, a coil or a low impedance between the neutral and the earth. This system can be found in Portugal, Spain and France. 
With this neutral system we can reduce the magnitude of current fault in a quickly and safely way.

The impedance value is always high when compared to the lines impedance. Therefore the system fault current varies with the fault. This current is approximately in the magnitude of hundreds of Ampere (100 A to 2000 A). This high value of fault current, as well as the preponderance of components circulating in the neutral impedance, makes it easier to detect earth faults.

In Fig. 3 we can see the case of a resistive component between neutral and earth. An alternative can be an inductive component (Fig. 4), to partially compensate the capacitive component of network [6].

The inductive impedance limits the fault current and overvoltage. However the protection must act automatically at the first earth fault. To easily detect the fault, the inductive current must be higher than the capacitive current that circulates in the system. In distribution systems inductive current values are between $300 \mathrm{~A}$ and $1000 \mathrm{~A}$, because they are easier to detect, thus preventing overvoltage's [1].
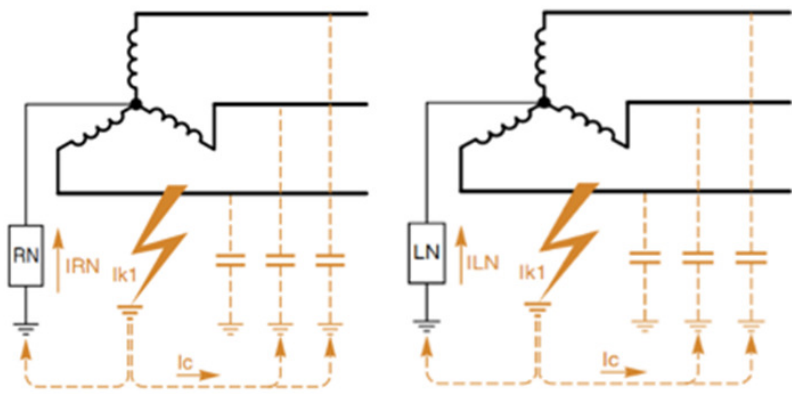

Figure 3 and 4. Resistive and Inductive Earthing, respectively

This system limits the range of fault currents and the protections are easy to implement if the current limit is greater than the system capacitive current. The coil has low resistance, and it does not dissipate a large amount of heat energy. In HV networks this solution is more preferred to the earth resistance one

\subsection{Petersen coil / Resonant grounded}

This ground system can be used in aerial or mixed lines, implying the installation of a Peterson coil in HV/MV substations [9].

The Petersen coil is also known as suppressor arcs, faults neutralizer or extinction coil. The systems with this neutral point are also known as neutral resonant or compensated systems [10].

A Petersen coil is usually connected to the neutral of the distribution transformer (Fig. 5), or connected to the zigzag transformer, so that the fault current is practically zero when a fault occurs [4]. The contribution to the fault current from the current capacity of the lines (where a ground fault circulates from a healthy conductor to the earth), is compensated by the current coil [7].

The inductance value of the Petersen coil must be equal to the capacities of the network, which may vary, as it happens when switching operations occur in the network. When this happens the system is fully compensated, or $100 \%$ tuned. The modern controllers constantly monitor the zero sequence voltage and detect any changes in the capacities of the network.

The controller will automatically adjust to the new level, ensuring that the Petersen coil is properly tuned to neutralize any ground fault that may occur [11]. This fast limitation of current fault occurs automatically without any intervention from another system [12].

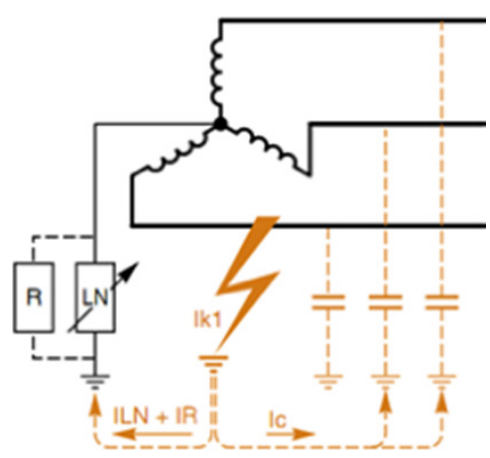

Figure 5. Petersen coil

The inductive and capacitive currents compensate each other provided that one is inductive (circuit ground) and the other is capacitive (healthy capacity lines). 
Currents may be added in opposite phases, due to a slight coil resistance with a magnitude of few Ampere.

\section{Case Study}

In this work, we use a $30 \mathrm{kV}$ distribution grid fed by SERPA substation in Portugal. The objective is to study and compare four different neutral systems giving special attention to the results obtained when using the Petersen coil. These systems are: Petersen coil, in two different situations; impedance grounded; and isolated neutral (ungrounded) - for direct faults and resistive faults. This study was supported by software used in Portuguese distribution utility. This software was used to obtain line voltage and current values after the occurrence of faults. Because the voltage triangle is relatively undisturbed, these systems can remain operational during sustained, low-magnitude faults. Self-extinction of ground faults in overhead-ungrounded lines is possible for low values of ground fault current.

\subsection{Modelling Petersen Coil}

In this case, the fault current is linked to the tuning coil which limits the fault to very low levels, but not exceeding 40A. The Petersen coil neutral system is studied here in two different situations.

In the first situation, the fault current is less than $40 \mathrm{~A}$ and in the second one it is below $20 \mathrm{~A}$. Ideally the tuning should be automatic, generating the lowest possible fault current.

In this study, the impedance value of the Petersen coil is a fixed value, determined as to limit the fault current to $40 \mathrm{~A}$, and $20 \mathrm{~A}$ for the two situations. The resistance value is ignored, because it has a very low value.

\subsection{Analysing Impedance Coil}

The values for the impedance are:

$$
\begin{gathered}
V_{c}=30000 \mathrm{~V} \\
V_{s}=\frac{V_{c}}{\sqrt{3}}=\frac{30000}{\sqrt{3}}=17321 \mathrm{~V}
\end{gathered}
$$

1) Impedance for $40 \mathrm{~A}$

$$
Z=\frac{V_{s}}{I}=\frac{17321}{40}=433,013 \Omega
$$

2) Impedance for $20 \mathrm{~A}$

$$
Z=\frac{V_{s}}{I}=\frac{17321}{20}=866,025 \Omega
$$

The selected network has the following characteristics:
a) Large network;
b) Overhead lines - 127854 m (215 m cables);
c) Rural network.

In Fig. 6 we can see five selected locations to take measurements, where 1 is location where the earth fault occurs, 3 is the fed substation and 5 is the furthest point away from the earth fault.

The fault current flows through locations 1, 2 and 3, whereas the other points only "see" the fault, and are affected by it.

For the neutral system using Petersen coil an impedance was used to limit the fault current to $20 \mathrm{~A}$ and $40 \mathrm{~A}$, respectively. A reactance was used in the isolated system to limit the fault current to $300 \mathrm{~A}$.

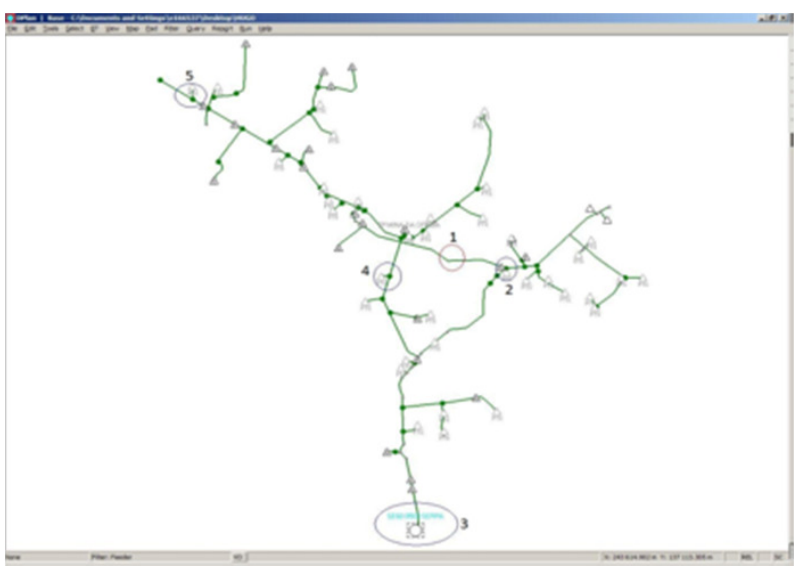

Figure 6. Study network

\subsection{Direct Faults}

In the following tables we present the voltage values in L1 line in fault (line-earth), and the values in other lines. Tables 1 and 2 refer to the case of using Petersen coil and limiting the fault current respectively to $40 \mathrm{~A}$ and $20 \mathrm{~A}$. 
Table 3 refers to the use of neutral reactance, and table 4 refers to the neutral isolated system.

Table 1. Petersen coil - $40 \mathrm{~A}$

\begin{tabular}{|c|c|c|c|c|c|c|c|}
\hline & \multicolumn{6}{|c|}{ Voltage } \\
\hline & & \multicolumn{2}{|c|}{ L1 } & \multicolumn{2}{|c|}{ L2 } & \multicolumn{2}{|c|}{ L3 } \\
\hline & & pu & angle $\left(^{\circ}\right)$ & $\mathrm{pu}$ & angle $\left({ }^{\circ}\right)$ & $\mathrm{pu}$ & angle $\left({ }^{\circ}\right)$ \\
\hline \multirow{5}{*}{ : } & 1 & 0 & 0 & 1,702 & $-148,6$ & 1,681 & 149,8 \\
\hline & 2 & 0,006 & $-29,7$ & 1,699 & $-148,6$ & 1,679 & 149,7 \\
\hline & 3 & 0,042 & $-31,6$ & 1,687 & $-148,2$ & 1,665 & 149,5 \\
\hline & 4 & 0,021 & $-30,6$ & 1,694 & $-148,4$ & 1,673 & 149,7 \\
\hline & 5 & 0,021 & $-30,6$ & 1,694 & $-148,4$ & 1,673 & 149,7 \\
\hline
\end{tabular}

Table 2. Petersen coil - 20 A

\begin{tabular}{|c|c|c|c|c|c|c|c|}
\hline & \multicolumn{6}{|c|}{ Voltage } \\
\hline & & \multicolumn{2}{|c|}{ L1 } & \multicolumn{2}{|c|}{$\mathrm{L} 2$} & \multicolumn{2}{|c|}{ L3 } \\
\hline & & $\mathrm{pu}$ & angle $\left(^{\circ}\right)$ & $\mathrm{pu}$ & angle $\left({ }^{\circ}\right)$ & $\mathrm{pu}$ & angle $\left({ }^{\circ}\right)$ \\
\hline \multirow{5}{*}{. } & 1 & 0 & - & 1,717 & $-149,3$ & 1,706 & 149,9 \\
\hline & 2 & 0,003 & $-30,3$ & 1,715 & $-149,3$ & 1,704 & 149,9 \\
\hline & 3 & 0,022 & $-32,3$ & 1,709 & $-149,1$ & 1,697 & 149,8 \\
\hline & 4 & 0,011 & $-31,3$ & 1,713 & $-149,2$ & 1,702 & 149,8 \\
\hline & 5 & 0,011 & $-31,3$ & 1,713 & $-149,2$ & 1,702 & 149,8 \\
\hline
\end{tabular}

Table 3. Inductive impedance

\begin{tabular}{|c|c|c|c|c|c|c|c|}
\hline & \multicolumn{6}{|c|}{ Voltage } \\
\hline & & \multicolumn{2}{|c|}{ L1 } & \multicolumn{2}{|c|}{ L2 } & \multicolumn{2}{|c|}{ L3 } \\
\hline & & $\mathrm{pu}$ & angle $\left({ }^{\circ}\right)$ & $\mathrm{pu}$ & angle $\left({ }^{\circ}\right)$ & $\mathrm{pu}$ & angle $\left({ }^{\circ}\right)$ \\
\hline \multirow{5}{*}{ 苛 } & 1 & 0 & - & 1,717 & $-149,3$ & 1,706 & 149,9 \\
\hline & 2 & 0,003 & $-30,3$ & 1,715 & $-149,3$ & 1,704 & 149,9 \\
\hline & 3 & 0,022 & $-32,3$ & 1,709 & $-149,1$ & 1,697 & 149,8 \\
\hline & 4 & 0,011 & $-31,3$ & 1,713 & $-149,2$ & 1,702 & 149,8 \\
\hline & 5 & 0,011 & $-31,3$ & 1,713 & $-149,2$ & 1,702 & 149,8 \\
\hline
\end{tabular}

Table 4. Isolated system

\begin{tabular}{|c|c|c|c|c|c|c|c|}
\hline & \multicolumn{6}{|c|}{ Voltage } \\
\hline & & \multicolumn{2}{|c|}{ L1 } & \multicolumn{2}{|c|}{ L2 } & \multicolumn{2}{|c|}{ L3 } \\
\hline & & $\mathrm{pu}$ & angle $\left(^{\circ}\right)$ & $\mathrm{pu}$ & angle $\left(^{\circ}\right)$ & $\mathrm{pu}$ & angle $\left(^{\circ}\right)$ \\
\hline \multirow{5}{*}{$\begin{array}{l}\overrightarrow{0} \\
0\end{array}$} & 1 & 0 & - & 1,732 & -150 & 1,732 & 150 \\
\hline & 2 & 0 & - & 1,732 & -150 & 1,732 & 150 \\
\hline & 3 & 0 & - & 1,732 & -150 & 1,732 & 150 \\
\hline & 4 & 0 & - & 1,732 & -150 & 1,732 & 150 \\
\hline & 5 & 0 & - & 1,732 & -150 & 1,732 & 150 \\
\hline
\end{tabular}

The fault occurs in location 1 , and location 2 is the closest point. In both points we can notice a strong interference in the respective voltage values. In fault line L1 the voltage drops to zero in local 1 , and practically to zero in local 2 , in all situations. As expected, in L2 and L3 lines voltage values rise in all different situations and network points.

This increased voltage values in healthy phases can damage some equipment isolation or reduce its life. In all situations we can observe a strong shift of the neutral point.

\subsection{Resistive Faults}

We also studied the impact of resistive faults in line-earth $\mathrm{L1}$ under three soil conditions. The fault impedance depends on the soil characteristics and the conditions when the fault occurs. Thus, we simulate the fault for the case of 10,500 and $1000 \mathrm{ohm}$. In the following figures we can see the voltage values in lines and let us analyze the drop voltages in each situation of the four neutral systems considered: BP40 - Peterson coil 40A, BP20 - Peterson coil 20A, REAN Inductive impedance and ISOLADO - isolated system.

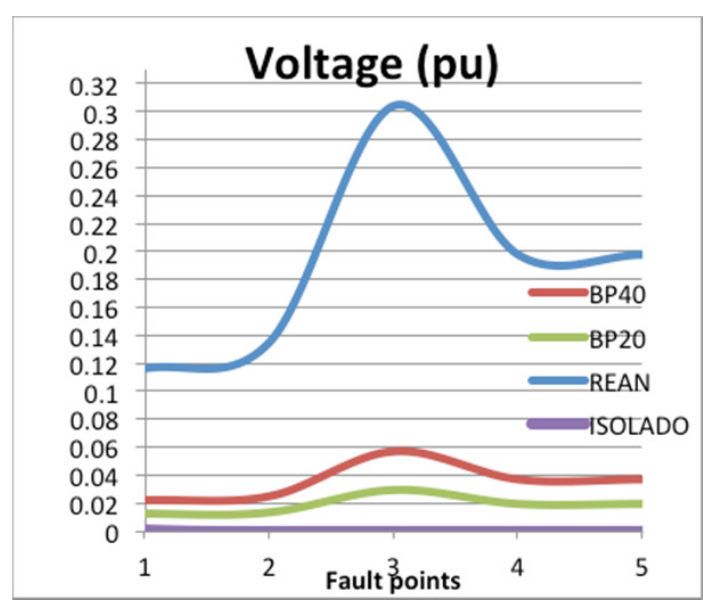

Figure 7. Resistive faults (10 $\Omega)$

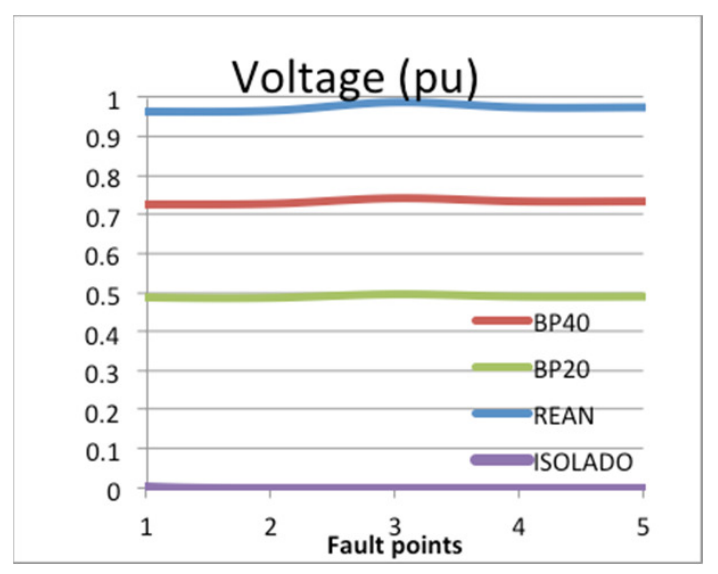

Figure 8. Resistive faults (500 $\Omega$ ) 


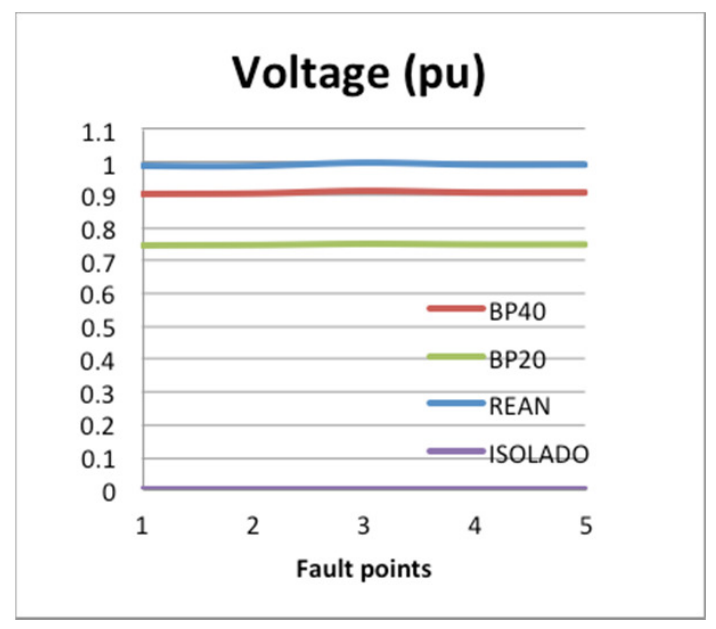

Figure 9. Resistive faults (1000 $\Omega)$

In the three different soil conditions we can notice that as the soil resistivity increases, the voltage drops. In Figs. 7 and 8 , drop voltage is very small, remaining very close to $1 \mathrm{pu}$.

Usually in resistive faults, the voltage increase in healthy lines is not so high as in the direct faults. That results in fewer problems in equipment insulation and lifetime. In both direct and resistive faults the neutral displacement occurs.

\section{Conclusions}

In direct faults, except in the case of the isolated neutral system in point 3, and for the remaining systems, it is visible a slight increase in voltage values, because point 3 is located in SERPA substation, which feeds the studied network. In all systems we can observe a strong displacement of the neutral point.

The default current is limited by the neutral at stake. In the case of the isolated neutral, default current is zero, because the fault loop does not close, and thus no fault current is generated. Using the Petersen Coil the fault current is limited to $40 \mathrm{~A}$ and $20 \mathrm{~A}$, respectively in the two simulated situations, which is one of the advantages this system, because in both we can practically eliminate the fault current when the coil is tuned.

After the fault occurrence, the voltage system becomes unbalanced, as shown in the previous tables.
This is because of the drop voltage in the faulty line and the healthy phases increase.

The neutral point using the reactance neutral is the situation in which voltage drops are not so high; however, the fault current is the highest.

In direct faults, as well as in resistive faults, the current is limited by the type of neutral system. The lower the fault current limit and the higher soil resistivity, the less is the voltage drop across the fault line (L1), and the lower increase in voltage in healthy lines (L2, L3), except for the neutral point isolated. In this case, upon the occurrence of a fault in phase L1, the healthy phases are always subject to line-toline voltage.

In both cases, for resistive and direct faults, displacement of neutral point does occur.

\section{Referências}

[1] Nelson, J. P. and Sen, P. K.: "System Grounding, Ground Fault Protection and Electrical Safety", IEEE Press Series on Power Engineering (Book 37), Wiley-IEEE Press; 1 edition, Jun. 2014

[2] Bjerkan, E., Venseth, T.: Locating Earth-Faults in Compensated Distribution Networks by means of Fault Indicators. International Conference on Power Systems Transients, Canada, 2005.

[3] Pühringer, M: Resonant Grounding as Approach to System Neutral Grounding. Haefely Trench, Feb. 1998.

[4] Roberts, J., Altuve, H.J., Hou, D.: Review of Ground Fault Protection Methods for Grounded, Ungrounded, and Compensated Distribution systems, 2001.

[5] Hou, D.: Comparing Fault Resistance Coverage of Different Distribution System Grounding Methods. 37th Annual Western Protective Relay Conference, October 2010.

[6] Fulchiron, D., "Basic selection of MV public distribution networks", Cahier technique no. 203, Schneider Electric, Maio 2001.

[7] Griffel, D.; Leitloff, V.; Harmand, Y.; Bergeal,J.; , "A new deal for safety and quality on MV networks", Power Delivery, IEEE Transactions on, vol.12, no.4, pp. 1428 -1433, Outubro 1997.

[8] Guldbrand, A.: System earthing. Industrial Electrical Engineering and Automation, Lund University, 2006.

[9] Escalier, S.; Raymongue, J.; Pinget. A.; Clément, M.; Jeanjean, R.: “Impédances de compensation pour la mise à la terre du neutre des réseaux HTA aériens et mixtes", Spécification Technique EDF, Outubro 2001.

[10] Grid, A., "Network Protection \& Automation Guide", Julho 2002, ISBN: 29518589-0-6

[11] HV Power, "Petersen Coils - Basic Principle and Application", Abril 2012.

[12] Dolnik, B., Kurrimsky, J.: Contribution to earth fault current compensation in middle voltage distribution networks, Przeglad Elektro-techniczny (Electrical Review), ISSN 0033-2097, R. 87 NR 2/2011. 